\title{
Analysis of Students' Perception on Quality of Management Education in Kathmandu
}

\author{
Aaratee Tripathee ${ }^{1}$
}

\begin{abstract}
This paper examines the students' perception on quality of MBA program and the relationship between the perceived quality and satisfaction of the students with the MBA program. For this study 250 respondents, 50 each from five universities, pursuing MBA degree were taken as sample and surveyed through structured questionnaire in the year 2016. Five variables are taken as the major quality indicators: quality of curriculum, faculty, employability, infrastructure, and reputation. For data analysis, descriptive, analytical and inferential techniques have been employed. The perceptions of the students are analyzed against the five quality dimensions where significant relationship is seen between the satisfaction of the students and faculty, employability, infrastructure and reputation. The study observed that a good brand name is often associated with quality and it is likely to think that good reputation is bound with good curriculum, faculty, employability and infrastructure. Hence, educational institutions should work on building good rapport in the market as it exerts strong effect on the overall satisfaction of students. This can be promoted by highlighting graduate employability and by indicating the career success and development of the graduates and alumni. The finding also revealed that the factors do affect the students' perception and among the selected five quality dimensions 'reputation' is seen as the most influential factor in forming students perception and 'curriculum' is seen as the least influential factor as there is not much difference in curriculum provided by different universities.
\end{abstract}

Keywords: perceived quality; MBA program; reputation and educational institutions

\footnotetext{
This paper was presented in the International Conference on Business, Society and Governance: Emerging Management Paradigm organized by Faculty of Management Studies, Pokhara University in February 2017 and in the International Conference on Emerging Trends and Issues in Management organized by Central Department of Management, Tribhuvan University in June 2017.

The researcher is indebted to Prof. Dr. Kundan D. Koirala (former dean of Tribhuvan University, Faculty of Management) and Dr. Ram K. Phuyal (Associate Professor, CEDA, Tribhuvan University) for their valuable insights and commendable supports in building this paper. She would also like to extend her gratefulness to Mr. Sohan B. Khatri (Faculty member of AIM) for his suggestion and guidance in the course of undertaking this research.
} 
Tripathee: Analysis of Students' Perception on Quality ...

\section{Introduction}

It seems that MBA is the choice for majority of students in Nepal who want to make their career in the management and administration sector, be it for other companies or starting their own startup and managing it. Nepal is a developing country and can be seen as a land of opportunities as there are many sectors with business prospects like manufacturing, agriculture, textiles, medicinal herbs and plants, tourism and so on. People are becoming more educated and aware about such opportunities. The extension of service sectors and emergence of corporate houses in Nepal have led to the growing preference for MBA program as it offers the development of soft skills and technical knowledge in managing business and operations. With modernizing business and economy, demand for trained and skilled managers has billowed the nation, making management among the most sought after courses.

There are different colleges and business schools affiliated to domestic and international universities which offer various types of management programs. With the exception of a few, almost all the business schools were established in the last one decade. And with relatively short history, MBA education in Nepal has carved its own niche, adopting modern teaching- learning methodology. These colleges and institutions in the verge of competition are trying to provide their own standard for teaching and learning. Such institutions are evaluated on the basis of quality education it provides which is determined by the factors such as infrastructure, faculty members, curriculum, employability etc. Students seeking MBA programs need to make selection among these institutions and they choose the one that they think provides the quality education program. In this selection process do the factors of quality affect the perception of students towards the quality of management education program? How is the relationship between perceived quality by the students and their satisfaction with MBA program? These are the questions that this research paper arises and intends to find the answer.

The prime motivation of this study is to provide a better understanding about the satisfaction level of students of MBA program in Kathmandu Valley and how the service providers can improve their qualities. Not many researches are conducted in Nepal in this particular field. The previous research conducted in Nepal only presents why students want to join MBA program and the factors that influence the view of public in general about the MBA program. This research, however, focuses on identifying the most influential quality factors that affects the perception of MBA students. The findings from this paper would be of significance to the educational institutions and government in enriching their knowledge and help in understanding in greater depth the factors influencing the selection process by the students while doing MBA programs in different institutions. It helps both the institutions and the 
government to develop new policies to attract more local students to pursue MBA degree in Nepal.

The remaining part of the paper is organized as follows: section two presents review of literature tracing the internationally recognized research done in the similar field with their major findings stating the research gap. Section three provides the conceptual framework and the research methodology by elaborating the research paradigm. Section four provide the in-depth analysis of data and discuss the research findings in relation to the research questions. The final section contains a summary of major findings along with the recommendations made to practitioner and for future research.

\section{Review of Literature}

Guha, Chattopadhyaya, and Mondal (2013) have conducted a study which focuses on the perception of undergraduates towards the choice of management institutions visa-vis management curricula and concludes with the impact of pricing on the demand of the B-School from the stakeholders' perspective in the form of student's opinion. Sarwar and Haque (2011) have examined the factors that influence students in selecting MBA program in various higher learning institutions in Malaysia and confirmed that the course and career information is by far the most important category of information during the selection of a specific higher education institution along with the influence of family and friends. Shrestha (2013) has explored how public in general who are exposed to stimuli of physical attributes draw meaning of perceived quality and perceived value of higher education program. This study identifies antecedents of perceived quality of education program from the perspective of the public and finds that public in general is not concerned with organizational and corresponding monitoring process but with the reputation and brand image of the institutions. Chantasuwanno and Suasungnern (2011) has indicated that the internal reason of respondents to continue to study MBA is to improve their specific knowledge skill \& career advancement and the external factor is the labor market.

Briggs (2013) has indicated four major desires that make people select an MBA: the desire to earn more money, to change careers, to advance their careers, and for knowledge. This research further identifies that the university's ability to help make them more marketable or advance their career as the most important factor in considering MBA program. Mwatsika and Khomba (2013) have discovered two new MBA service quality criteria that include management of MBA program and image which are not conceptualized for measurement in existing service quality models. The study is carried using SERPERF and HEdPERf models that designate that using the top-of- mind technique of respondents may offer useful insights for managers and practitioners to formulate specific strategies to improve attractiveness and 
competitiveness of the service provided. Sulaiman and Mohezar (2008) have indicated that MBA increases the learning skills of its participants and they value the contributions of the teaching staff and the curriculum content highly. Nandekar (2014) has used factor analysis to measure the constructs and observed that MBA curriculum is suitable for making students future managers, MBA curriculum develops the confidence in students of being an employee but not a leader, a requirement of today's world.

Ho and Hung (2008) have revealed that the five most important factors for students' school selection are: employability, curriculum, academic reputation, faculty, and research environment. Mang'unyi and Govender (2014) have illustrated the relationship between service quality and customer satisfaction using HEdPERf Model comprising non-academic, academic, reputation, access, programme issues and understanding aspects of service quality. The study has showed that these dimensions have a positive and significant relationship with service quality and in turn influence customer satisfaction.Osman and Mohammad (2014) through the gap analysis model shows that though the student enrollment have a good prospect, majority of university are not maintaining quality education due to the noncompliance with the statutory requirements. Further the study finds that between aesthetic and performance factors, the latter has higher influence on the satisfaction of the students towards the MBA program. Pokhrel, Tiwari, and Phuyal (2016) have revealed that the most important influencing factor for admission at the BBA and MBA levels is recommendations made by friends. However, the word of mouth from family, relatives, colleges' website and newspapers' advertisements are also found to be effective.

Previous research conducted as per the above literature review identifies that consumer view MBA as advanced program to develop necessary skills and increase knowledge. The reason behind enrollment is the opportunities and good prospects, high remuneration and skills that MBA showcase after graduation. Those researches conducted only present why students want to join MBA program and the factors that influence the view of public in general about the MBA program. This paper however focuses on identifying if the quality factors affect the perception of students while selecting the management program and if yes which is the most influential factor? Although it is widely acknowledged that there is a need for quality indicators of every educational programs, very little research in this area exists in Nepal. Therefore this study attempts to minimize this existing research gap. 


\section{Methodology}

\subsection{Conceptual Model}

Conceptual framework must demonstrate an understanding of theories and concepts that are relevant to the topic of research paper and can be measured. The conceptual framework is developed with reference to the paper, Shrestha (2013). This study identifies antecedents of perceived quality of education program from the perspective of the public. The survey explores how public in general who are exposed to stimuli of physical attributes such as physical facilities and symbolic attributes such as employability, faculty, curriculum, infrastructure and reputation understand and draw meaning of perceived quality of management program. The framework presented here shows different parameters that affects the quality of education.

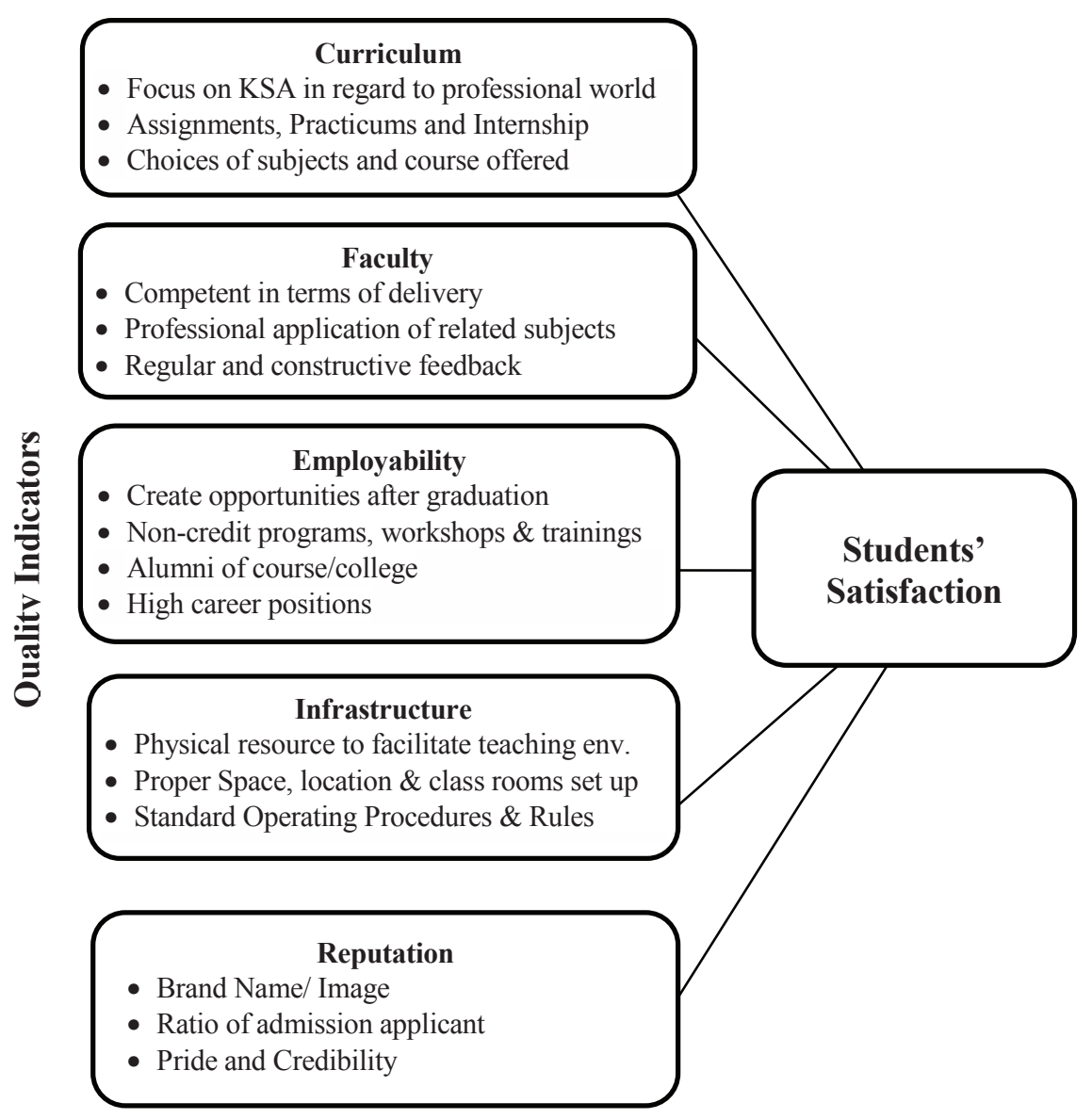

Figure 1: Conceptual framework 
Tripathee: Analysis of Students' Perception on Quality ...

\subsection{The Data}

Data has been collected through a structured questionnaire comprising of three parts. Part 1 of the questionnaire consists of 7 items on demographic profiles of the respondents like age, gender, marital status, profession, place of SLC origin and educational background. Part 2 consists of 5 items with 21 statements pertaining how students have perceived the quality of MBA program in align with five quality indicators: curriculum, faculty, employability, infrastructure and reputation as shown in the conceptual framework above.

Part 3 consists of three items about the overall experience with the MBA program like the satisfaction with the MBA program, the most important quality factor in the selection process and the value for money. The convenience sampling technique has been followed to collect data. The sample comprises of 250 students of MBA program from different colleges affiliated to five renowned universities: Tribhuvan University (SOMTU), Kathmandu University (KU), Pokhara University (PoU), Purbanchal University (PU), and one Foreign University. These are the final year students pursuing MBA degree in different universities, some have recently graduated. 50 students from five different universities are chosen as a sample for the study. In this study, each item is measured based on Likert Scale. The scale involves respondents being asked to state their level of agreement with a series of statements about quality indicators. The respondent indicates agreement by selecting one of the following descriptors; strongly disagree, disagree, neutral, agree, strongly agree. Likert Scale is a discrete scale because only the values 1,2, 3, 4 , or 5 can be assigned. The most popular test of inter item consistency reliability is the Cronbach's coefficient alpha which is used for multipoint-scaled items. The higher the coefficients, the better the measuring instrument (Sekaran, 2003). The present study finds Cronbach's alpha value as 0.82 for 22 items in the construct. Zikmund et al. (2010) have mentioned that scales with a coefficient alpha above 0.60 are considered to have good reliability.

\subsection{Data Analysis Methods}

An instrument developed for measuring different attributes of quality of management education program is used for this study. This instrument contains twenty one statements for measuring five quality indicators. Four statements are used for measuring the quality of curriculum, four statements for quality of faculty, four statements for employability, four for quality of infrastructure and five statements for reputation. This instrument is reported to have sufficient reliability and validity indicators. Descriptive statistics, correlation matrix and multiple regressions have been employed to analyze data by SPSS 20.0 version. 
Descriptive data, presented in table 1, summarizes the sample with the help of demographic variables describing the nature of the samples taken like the gender which shows the number of male and female respondents, the number of samples in different age group, their educational background etc. Correlation analysis describes the nature of relationship (positive or negative) and the degree to which the variables are associated (weak or strong). Regression analysis includes many techniques for modeling and analyzing several variables, when the focus is on the relationship between a dependent variable and one or more independent variables. It helps one to understand how the typical value of the dependent variable changes when any one of the independent variables is varied, while the other independent variables are held fixed. In this study, the researcher uses the regression analysis to understand how the overall satisfaction (dependent variable) is predicted by the other independent variables which, in this case, is curriculum, faculty, employability, infrastructure and reputation.

\section{Results and Discussion}

The results suggest that the factors of quality do affect the perception of students towards the quality of MBA program and among the five selected quality indicators 'reputation' is seen as the most influential factor. Among the five statements of hypothesis, all other hypothesis are rejected except $\mathrm{H}_{0} 1$ which indicates that curriculum does not play a role in satisfying student towards the management program offered by various colleges. The results from different modeling techniques are shown in details in the sub section below.

\subsection{Descriptive Statistics}

The study shows that most of the students are satisfied with the quality of MBA program. Quality indicators such as curriculum, faculty, employability, infrastructure and reputation are found to be equally important to influence student's choice. Among all the factors reputation is seen as the most important quality factors (mean 3.21) and infrastructure is seen as the least important quality factor (mean 2.81) even though it provides a visual commitment of college and universities in providing quality education. Reputation scores highest means which shows a positive perception towards the reputation followed by infrastructure, employability, curriculum and faculty. 
Tripathee: Analysis of Students' Perception on Quality ...

Table 1: Demographic profile

\begin{tabular}{llcc}
\hline & Classification of variable & Frequency & Percentage (\%) \\
\hline \multirow{4}{*}{ Age } & $21-25$ & 13 & 5.2 \\
& $26-30$ & 127 & 50.8 \\
\multirow{4}{*}{ Gender } & $31-35$ & 98 & 39.2 \\
\multirow{4}{*}{ Marital Status } & $36-40$ & 12 & 4.8 \\
& Male & 141 & 56.4 \\
\multirow{4}{*}{ Profession } & Female & 109 & 43.6 \\
& Married & 76 & 30.4 \\
\multirow{3}{*}{ Place of SLC Origin } & Unmarried & 174 & 69.6 \\
& Part Time & 34 & 13.6 \\
\multirow{2}{*}{ Educational Background } & Full Time & 151 & 60.4 \\
& Business/ Self Employed & 55 & 22.0 \\
& Unemployed & 10 & 4.0 \\
& Kathmandu Valley & 145 & 58.0 \\
& Outside Kathmandu Valley & 105 & 42.0 \\
& Management & 181 & 72.4 \\
\hline
\end{tabular}

\subsection{Correlation Analysis}

Through the observation of correlation analysis, it is realized that reputation is highly correlated with the quality of MBA program $(0.48)$ as shown in table 2 . The college's brand name shows a positive impression in regard to the quality of education it provides among the corporate and industry players. Employability is highly related to the program quality $(0.351)$. The non credit courses, workshops, internships and trainings seem to inculcate employability skills among students making them more eligible to perform in the market. Infrastructure $(0.26)$ and faculty $(0.16)$ also show a positive correlation with the quality of the program. The proper space and location, classroom setup, library and labs are assets that allow for smooth functionality to run the entire program which is again a quality indicator. The faculty's knowledge of professional application and demonstration of subject matters has direct impact on the learning of students. All these play a vital role in the overall satisfaction with the program. Curriculum, however, has a weak correlation with the quality of program (0.07). This might be because there is not much differences in the curriculum for MBA provided by different colleges. 
Table2: Mean and SD rank of the most important quality factors

\begin{tabular}{lll}
\hline Quality Indicators & Mean & Std. Deviation \\
\hline Rank of Curriculum & 3.00 & 1.367 \\
Rank of Faculty & 2.99 & 1.386 \\
Rank of Employability & 2.98 & 1.403 \\
Rank of Infrastructure & 2.81 & 1.387 \\
Rank of Reputation & 3.21 & 1.515 \\
\hline
\end{tabular}

\subsection{Regression Analysis}

The results from regression analysis show that the overall satisfaction of the students with the quality of the MBA program is predicted by the students perception of the five quality dimensions namely Curriculum $(\beta 1=0.157, p<0.05)$, Faculty $(\beta 2=0.292$, $p<0.05)$, Employability $\left(\beta_{3}=0.672, p<0.05\right)$, Infrastructure $\left(\beta_{4}=0.498, p<0.05\right)$ and Reputation $\left(\beta_{5}=1.031, \mathrm{p}<0.05\right)$. Here the coefficients or the beta value for all dimensions, given in the table 3, explains how much is the change in the dependent variable vis a vis change in the predictor variables. The beta value for reputation dimensions is the highest i.e. 1.03, which means that it has higher influence on the satisfaction of students. Higher beta value indicates more influence on dependent variable. Hence, it is very essential that the universities and colleges should focus on this dimension as it exerts strong effect on the overall satisfaction level of the program on students. Taken as a whole, we can see that except curriculum all other four quality dimensions show significant relationship with the overall satisfaction level as the $p$ values are less than the significance level in these four cases.

Table 3: Summary of analysis of quality indicators

\begin{tabular}{|c|c|c|c|c|c|c|}
\hline Hypothesis & & $\begin{array}{l}\text { Effects } \\
(Y=a+b X+e)\end{array}$ & $\mathbf{R}^{2}$ & $\begin{array}{l}\text { Constant } \\
(\beta 0)\end{array}$ & $\begin{array}{l}\text { Coefficient } \\
(\beta i)\end{array}$ & Remarks \\
\hline $\mathrm{H}_{0} 1$ & $\begin{array}{l}\text { There is no significant } \\
\text { relationship between } \\
\text { curriculum and overall } \\
\text { students' satisfaction. }\end{array}$ & CURRI $\rightarrow$ OS & 0.006 & 3.007 & 0.157 & Accepted \\
\hline $\mathrm{H}_{0} 2$ & $\begin{array}{l}\text { There is no significant } \\
\text { relationship between } \\
\text { faculty and overall } \\
\text { students' satisfaction }\end{array}$ & $\mathrm{FAC} \rightarrow \mathrm{OS}$ & 0.027 & 2.541 & 0.292 & Rejected \\
\hline $\mathrm{H}_{0} 3$ & $\begin{array}{l}\text { There is no significant } \\
\text { relationship between } \\
\text { employability and } \\
\text { overall students' } \\
\text { satisfaction }\end{array}$ & EMPLO $\rightarrow$ OS & 0.123 & 1.155 & 0.672 & Rejected \\
\hline
\end{tabular}


Tripathee: Analysis of Students' Perception on Quality ...

\begin{tabular}{|c|c|c|c|c|c|c|}
\hline $\mathrm{H}_{0} 4$ & $\begin{array}{l}\text { There is no significant } \\
\text { relationship between } \\
\text { infrastructure and } \\
\text { overall students' } \\
\text { satisfaction }\end{array}$ & $\mathrm{INFRA} \rightarrow$ OS & 0.068 & 1.741 & 0.498 & Rejected \\
\hline $\mathrm{H}_{0} 5$ & $\begin{array}{l}\text { There is no significant } \\
\text { relationship between } \\
\text { reputation and overall } \\
\text { students' satisfaction }\end{array}$ & $\mathrm{REP} \rightarrow \mathrm{OS}$ & 0.238 & -0.402 & 1.031 & Rejected \\
\hline
\end{tabular}

\section{Concluding Remarks}

The finding shows that reputation is seen as the most important factor that determines quality and infrastructure is the least important factor among the selected five different quality attributes. Demographic constructs like university, age group, place of SLC origin and educational background do not affect the satisfaction level of the students but variables like gender and marital status show a significant association. Females and married respondents are found to be more satisfied with the quality of MBA program. Among the five quality dimensions, again reputation is seen as the prime influential factor in forming the perception of students towards the quality and the satisfaction level with the MBA program whereas curriculum is seen as the least influential factor.

In a nutshell, today Nepal is recognized as a potential business place yet to be explored. With these opportunities, many business schools and institutions are thriving in Nepalese education sector and lots of students are attracted towards the MBA program. With the increasing enrollment of students in MBA program and increasing rate of colleges offering MBA, the relationship between quality and students satisfaction has been the concern of many previous studies in the educational field. Students get more options to choose and they have become more peculiar in choosing the right institution for them. They focus on the uniqueness and the quality of the management programs that one has to offer. Hence, it has become crucial for educational institutions to understand what affects the perception of students and how educational institution can improve themselves in attracting those students. The research suggests that there is a positive relationship between perception of quality of MBA programs and the overall satisfaction. Students satisfaction depends largely on ensuring that the college and universities maintain high quality standards because MBA is seen as a advance program that build professionalism and creates opportunities for job and entrepreneurship. A good brand name is often associated with quality. Quality assures good service, favorable environment, creates opportunities, improves skills and advances career. Hence, educational institutions should work on building good rapport in the market which can be done by promoting and highlighting graduate employability by indicating the career success and development of their graduates and alumni. 


\section{References}

Briggs, L. P. (2013). Factors prospective students consider when selecting an MBA program. University of South Florida. Retrieved from http://scholarcommons. usf.edu/etd/4446

Chantasuwanno, S., \& Suasungnern, S. (2011). The motivation and satisfaction of the students towards MBA at Karlstad University. Karlstad University, Sweden. Retrieved from http://www.divaportal.

Guha, P., Chattopadhaya, S., \& Mondal, D.K. (2013). Study on the perception of undergraduates towards MBA education with reference to Kolkata region, International Journal of Advance Research in Computer Science and Management Studies, 1(7), 33-42.

Ho, H.F., \& Hung, C.C. (2008). Marketing mix formulation for higher education: An integrated analysis employing analytic hierarchy process, cluster analysis and correspondence analysis. International Journal of Educational Management, 22(4), 328-340.

Mang'unyi, E.E., \& Govender, K.K. (2014). Perceived service quality (SQ) and customer: Student's perception of Kenya private university. Mediterranean Journal of Social Sciences, 5(23), 2793-2748.

Mwatsika, C., \& Khomba, K.J. (2013). Understanding MBA service quality in postgraduates' own terms: An exploratory analysis of top-of-the mind definition. African Journal of Business Management, 7(44), 4407-4419.

Nandekar, T. (2014). A study of perception of students towards present MBA curriculum with respect to being future managers and future businessmen. Indian Journal of Applied Research, 4(6), 12-15.

Osman, A.Z., \& Mohammad, A. A. (2014). A quality probe of the private MBA program: Evidence from Bangladesh. United International University. Journal of Education and Practice, 5(23), 58-66.

Pokhrel, S., Tiwari, A. \& Phuyal, R.K. (2016). An Impact of Education Marketing on Enrolment of Students at Private Management College in Kathmandu. Journal of Business and Social Science Research, 1(1), 21-32.

Sarwar, A., \& Haque, A. (2011). Factors Influencing in Selection of MBA Programs: An Empirical Investigation in Malaysian Higher Learning's Institutions. Conference Paper presented at 10th International Conference of the HRD (Asia Chapter). Paper no- AC-148-FRP. 
26 Tripathee: Analysis of Students' Perception on Quality ...

Sekaran, U. (2003). Research methods for business: A skill building approach (4 ed.). New York: John Wiley \& Sons Inc.

Shrestha, B.K. (2013). Public perception of the quality of academic program. Journal of Education Research, 3(1), 52-64.

Sulaiman, A., \& Mohezar, S. (2008). Quality in an MBA program: Student's Perception. International Journal of Management Education, University of Malaya, 7(2), 1-8.

Zikmund, W. G., Babin, B. J., Carr, J. C., \& Griffin, M. (2010). Business research methods (8th ed.). Mason, HO: Cengage Learning. 